\title{
Improved Water Consumption at the Sishen Tailings Storage Facility Complex
}

\author{
J.C.J. Boshoff SRK Consulting, South Africa \\ T. Kleinhans Sishen Iron Ore Mine, South Africa
}

\begin{abstract}
Tailings material from the existing Sishen plant is currently being deposited on four individual tailings dams. The solids concentration of the tailings can not be increased by means of thickening as the current process can not deal with flocculant. Decant water from each tailings dam is transferred into two seepage sumps via gravity penstock decant systems from where the water is returned back to the Sishen plant. The water balance and water recovery for the current Sishen tailings disposal system is not optimised and the dams are used on a random basis for the storage of storm rainfall and excess process water. The deposition cycle on the dams in terms of layer thicknesses and cycle times was not optimised. Significant evaporational losses therefore occur which is not ideal for an operation in such an arid climate.

The Sishen Expansion Project (SEP) involves the establishment of a separate process plant. Tailings material from the SEP plant will be disposed off in the cross area in between the current four individual tailings dams. One leg of the cross area will be closed off at a time and filled with SEP tailings materials. It is planned to fill the four legs of the cross area over a period of approximately 10 to 12 years. The SEP will increase the current water consumption and has prompted the optimisation of the tailings dam complex water balance.
\end{abstract}

Once the cross area is filled up to the same level of the four individual tailings dams, the four dams and the filled cross area will be consolidated into one single dam with four operating paddocks. The principle of operating four paddocks with optimised deposition strategies and small pool areas contributes towards improved water recoveries. The method of tailings disposal and dam operation also remains the same as per the current operations.

A return water dam (RWD) will be constructed as part of the SEP. The RWD will consist of an operating compartment capable of containing five days operational storage. Any run-off water from a 1:50 year 24 hour rainfall event on top of the tailings dams will be contained on top of the tailings dams and decanted in the shortest period of time possible.

This paper will discuss how the water consumption of the Sishen tailings dam complex was improved by conventional means other than thickened tailings. The improved water consumption over the life of mine will also be discussed.

\section{Introduction}

The Sishen Iron Ore Mine is located approximately $50 \mathrm{~km}$ south west of Kuruman in the Northern Cape Province, South Africa.

The existing Sishen tailings dam complex was built in the 1970s and is located to the north of the existing Sishen plant. The tailings material from the new Sishen Expansion project (SEP) plant will be disposed of in the cross area in between the four existing tailings dams. Increased water consumption as a result of the commissioning of the new plant was raised as a concern. It was therefore decided to optimise the current tailings dam complex and future disposal options in terms of water consumption. 


\section{Background}

Tailings material from the existing Sishen plant is currently being deposited on four individual tailings dams.

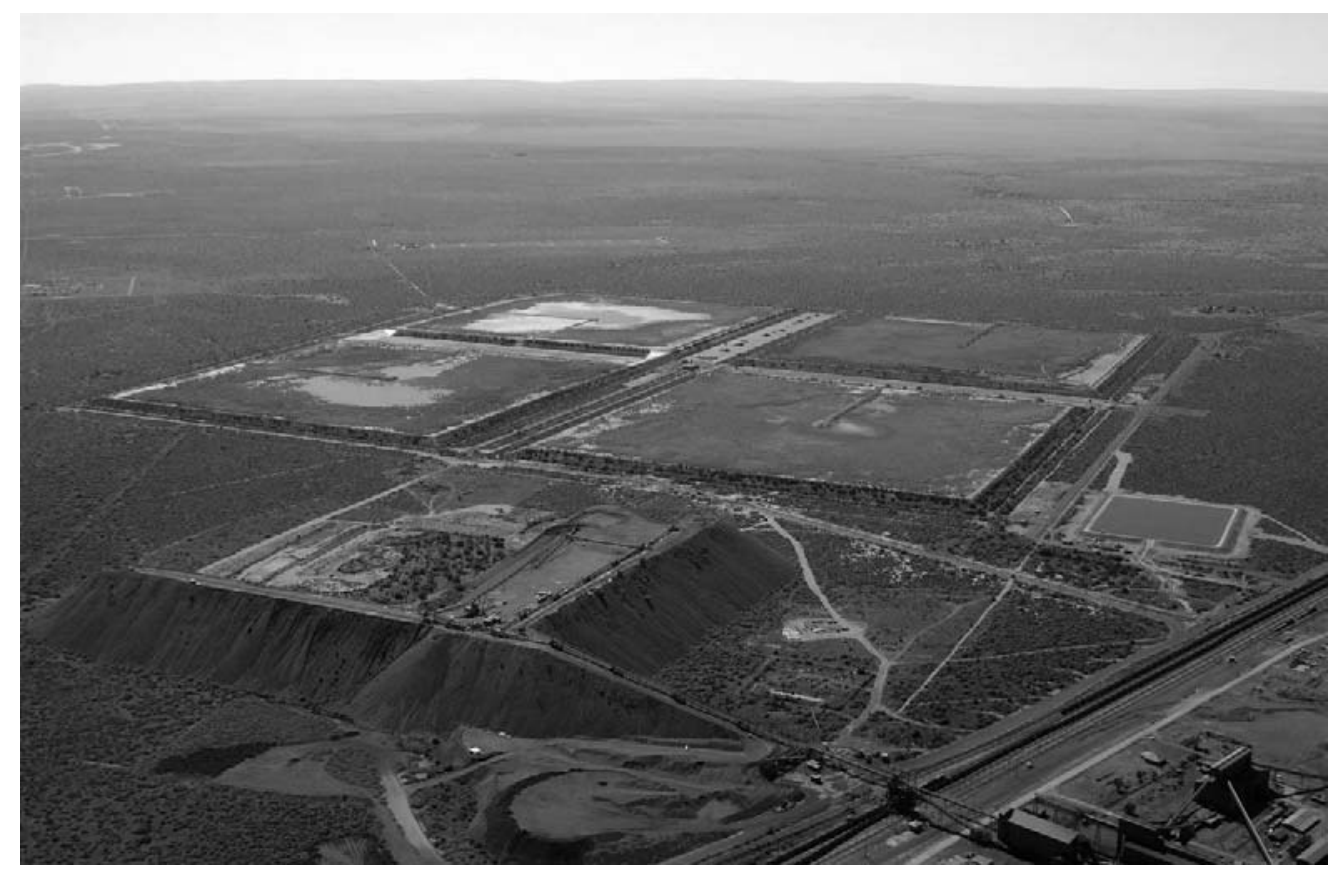

\section{Figure 1 Sishen TSF complex}

Decant water from each tailings dam was transferred into two seepage sumps via gravity penstock decant systems from where the water was returned back to the Sishen plant. The seepage collection sumps and pumps were not sufficient enough in terms of pumping rates which resulted in large volumes of water being stored on the tailings dams.

The water balance and water recovery for the current Sishen tailings disposal system was not optimised and the dams were used on a random basis for the storage of storm rainfall and excess process water. These issues were however addressed as part of the SEP especially the improvement on water recoveries.

The SEP involved the establishment of a separate process plant. Tailings material from the SEP plant will be disposed off in the cross area in between the current four individual tailings dams. One leg of the cross area will be closed off at a time and filled with SEP tailings materials. It is planned to fill the four legs of the cross area over a period of approximately 10 to 12 years.

Once the cross area is filled up to the same level of the four individual tailings dams, the four dams and the filled cross area will be consolidated into one single dam with four operating paddocks. The principle of operating four paddocks contributes towards improved water recoveries. The method of tailings disposal and dam operation also remains the same.

A return water dam (RWD) was also constructed as part of the SEP. 


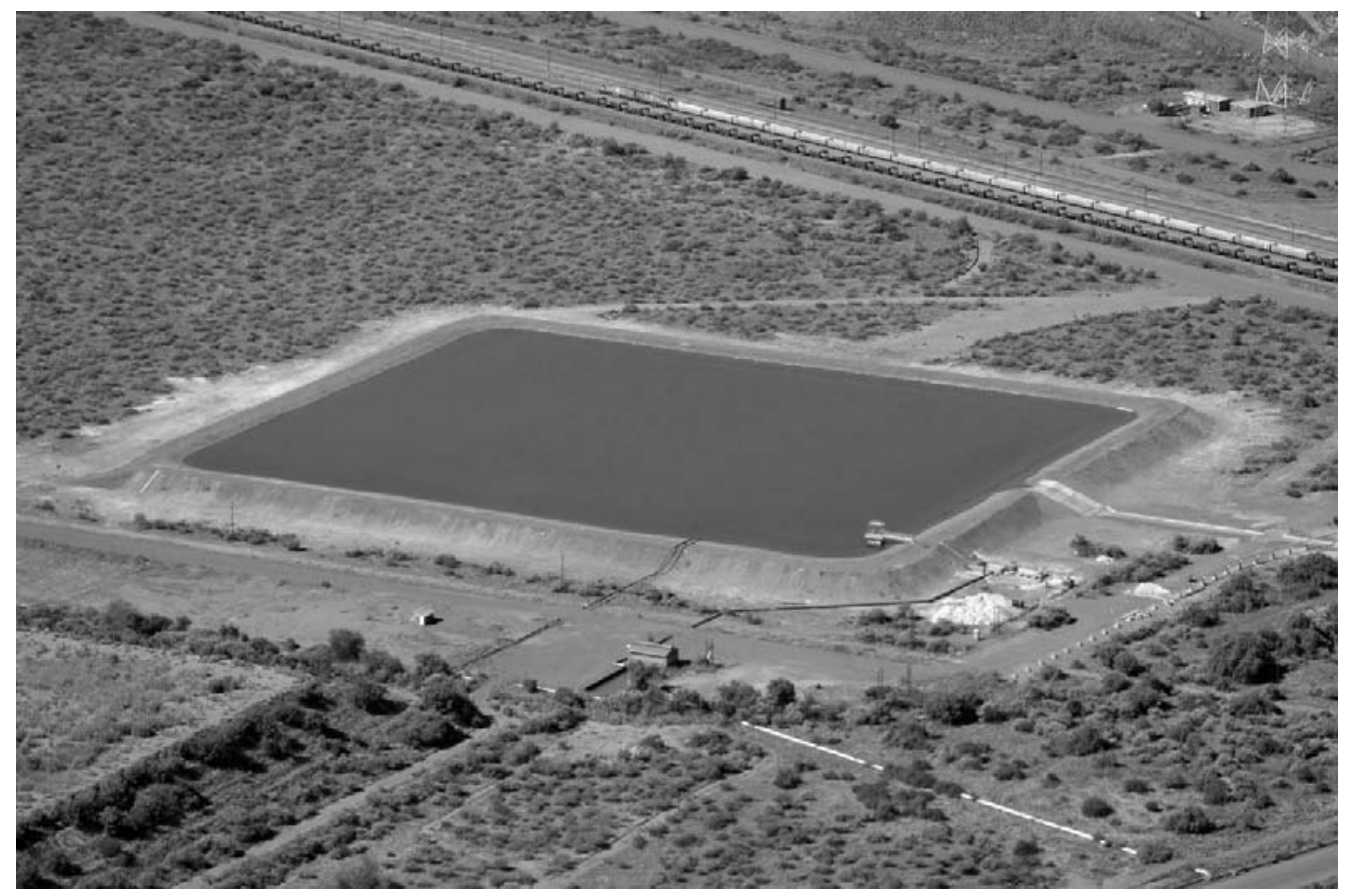

\section{Figure 2 New return water dam}

The RWD consists of an operating compartment capable of containing five days operational storage. Any run-off water from a 1:50 year 24 hour rainfall event on top of the tailings dams will be contained on top of the tailings dams and decanted in the shortest period of time possible. This is seen as a low risk area due to the low annual rainfall in the area.

The mining operation at Sishen Iron Ore Mine is by open pit mining and it is impractical for the tailings to be deposited in the workings. The existing four tailings dams and the cross area in between the four dams will be utilised for current and future tailings disposal.

\section{$3 \quad$ Weather data}

Monthly precipitation for the Sishen area has been obtained from the South African Weather Bureau. The Mean Annual Precipitation (MAP) for the site is approximately $354 \mathrm{~mm}$ per annum, which is extremely low.

The majority of the rainfall occurs during the summer months of January, February and March, whilst the lowest rainfall occurs during the months of June, July and August.

The mean annual S-pan evaporation in the Sishen area is $2,350 \mathrm{~mm}$.

\section{$4 \quad$ The Sishen process}

Sishen use Ferrosilicon as media in their Dense Media Separation (DMS) plant. Separation takes place at densities of $3.8 \mathrm{t} / \mathrm{m}^{3}$ and at these densities the plant are running on the limit of what the media stability allow. Any increase in un-stability will result in media segregation with a negative impact on separation efficiency. The only way to counteract this will be to lower the separation density which will result in off-grade product or as alternative in certain kinds of ore excluded from plant feed. This will negatively impact the available reserve, increase the stripping ratio and ultimately the life of the Sishen mine.

With the integrated water system, the use of flocculants in either the DMS plant or the new SEP plant will have such a negative impact on the stability of the ferrosilicon, thus ruling out any tailings handling system that require the use of flocculants. This therefore excludes the possibility of considering thickened tailings technology for the current Sishen plant and tailings dams.

The new SEP plant does not have this limitation as the process differs and therefore offers the possibility of a thickened tailings system in the future. 


\section{$5 \quad$ Modified deposition strategy}

The deposition strategy and dam development of the Sishen and SEP tailings disposal facilities will focus on two distinct phases, namely dam development prior to consolidation which will involve the operation of five individual dams and dam development after consolidation which will involve the operation of a consolidated dam divided into four paddocks.

During the pre-consolidation phase, tailings from the Sishen plant will be deposited on the existing four individual dams and tailings from the SEP plant will be deposited in the four legs of the cross area in between the existing four dams.

The four legs of the cross area will be filled with tailings material one at a time. Both ends of each leg will be closed off with waste rock containment walls up to the same level of the existing tailings dams at that point in time. Leg 1 will be closed off as part of the SEP project. The three remaining legs will however be closed off by the mine over time as and when required. Each leg will have an under-drainage system and gravity penstock decant system in order to maximise water return to the plant.

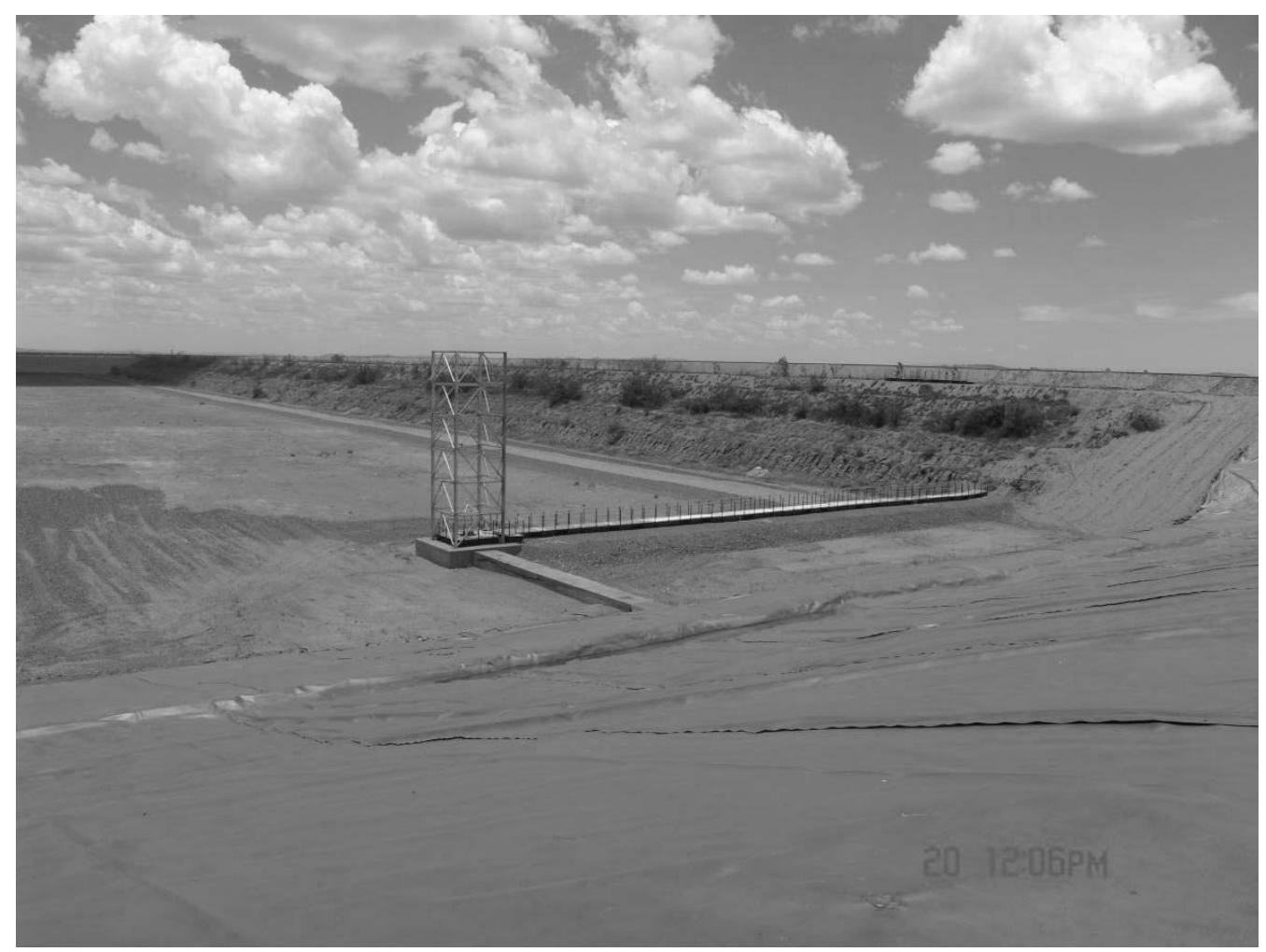

\section{Figure 3 Leg 1 closed with waste rock walls}

During the pre-consolidation phase, the four individual dams and the legs of the cross area will undergo partial consolidation in a phased approach in preparation for final consolidation. It is recognised that the current four individual dams will increase in height as the cross area is filled up over a period of time. The height of the waste rock containment walls to be installed will therefore also increase in height as time progresses.

During the post consolidation phase, tailings from both the Sishen and SEP plants will be deposited on the consolidated tailings dam. The consolidated tailings dam will be divided into four paddocks and tailings will be deposited on one paddock at a time. 


\section{Material properties}

The main material characteristics of the two tailings streams are:

- $\quad$ Solids specific gravity $=4.1$.

- $\mathrm{d}_{85}=20$ micron.

- $\mathrm{d}_{50}=50$ micron.

- Sishen slurry density $=1.3 \mathrm{t} / \mathrm{m}^{3}$ and Sishen average production rate $=170 \mathrm{ktpm}$.

- SEP slurry density $=1.5 \mathrm{t} / \mathrm{m}^{3}$ and SEP average production rate $=84 \mathrm{ktpm}$.

\section{$7 \quad$ Improved water recovery}

During the future tailings dam operations and development, the emphasis will be on the recovery and return of water back to the plant.

In order to maximise the return of water back to the plant, the following aspects were implemented on the tailings dam complex:

- The pool on any compartment or leg of the cross area should not exceed 5 to $7 \%$ of the surface area of the particular deposition facility. This will assist with the reduction in evaporational losses.

- Deposition on each dam should occur in layers not exceeding $350 \mathrm{~mm}$. This will result in a relatively quick deposition cycle therefore maintaining a large area of the top surface wet.

- The mine should consider depositing on more than one compartment simultaneously.

- The return water dam has been designed as a single compartment dam to operate only as a water holding facility for operational purposes. No standby compartment to contain the 1:50 year storm run-off has been allowed for. The run-off from a 1:50 storm event will be contained on top of the tailings dams and decanted in the shortest time possible. Freeboard on the tailings dams should therefore at all times conform to the legal freeboard requirements.

The water balance for the tailings dam complex was developed based on the above aspects.

Water balances were developed for a few scenarios in order to determine the life of mine water consumption. The scenarios that were considered are:

- Scenario 1 - Optimise the current Sishen complex in terms of the aspects above. Slurry density (SD) $=1.3 \mathrm{t} / \mathrm{m}^{3}$.

- Scenario 2 - Existing Sishen operation ( $\mathrm{SD}=1.3)$ without any improved water recovery aspects PLUS the new SEP tonnages ( $\mathrm{SD}=1.5$ ) on one footprint considering future consolidation of dam footprint.

- Scenario 3 - Optimised Sishen operation ( $\mathrm{SD}=1.3$ ) PLUS the new SEP tonnages ( $\mathrm{SD}=1.5$ ) on one footprint considering future consolidation of dam footprint.

- Scenario 4 - Existing Sishen operation ( $\mathrm{SD}=1.3$ ) without any improved water recovery aspects PLUS the new SEP tonnages on two separate footprints. SEP material thickened to a slurry density of $1.9 \mathrm{t} / \mathrm{m}^{3}$.

- Scenario 5 - Similar to scenario 2 but with Sishen and SEP material at a slurry density of $1.5 \mathrm{t} / \mathrm{m}^{3}$ in 10 years time. 
A summary of the water consumption figures for the various scenarios are as follows:

\section{Table 1 Water consumption figures for the various scenarios}

\begin{tabular}{ll}
\hline Scenario & $\begin{array}{l}\text { Water Consumption Over } \\
\left.\text { LoM ( } \mathbf{m}^{\mathbf{3}} / \mathbf{m o n t h}\right)\end{array}$ \\
\hline Scenario 1 & 120,363 \\
Scenario 2 & 118,556 \\
Scenario 3 & 150,428 \\
Scenario 4 & 151,848 \\
Scenario 5 & 142,969 \\
\hline
\end{tabular}

It is evident from the data in the table above that the mine has already benefited from the optimisation of the existing tailings dam complex in terms of water consumption. Although the SEP stand alone paste option along with the optimised Sishen solution makes the most sense from a water consumption point of view, it was decided to combine the two streams on one footprint due to capital and time constraints. This option however will be considered as part of future expansions. The selected option resulted in a life of mine water consumption of approximately $151,848 \mathrm{~m}^{3} /$ month. This will reduce to approximately $142,969 \mathrm{~m}^{3} / \mathrm{month}$ should the Sishen slurry density be increased to $1.5 \mathrm{t} / \mathrm{m}^{3}$. The impact of the additional consumption as a result of the new SEP plant was therefore minimised. Also see the figure below.

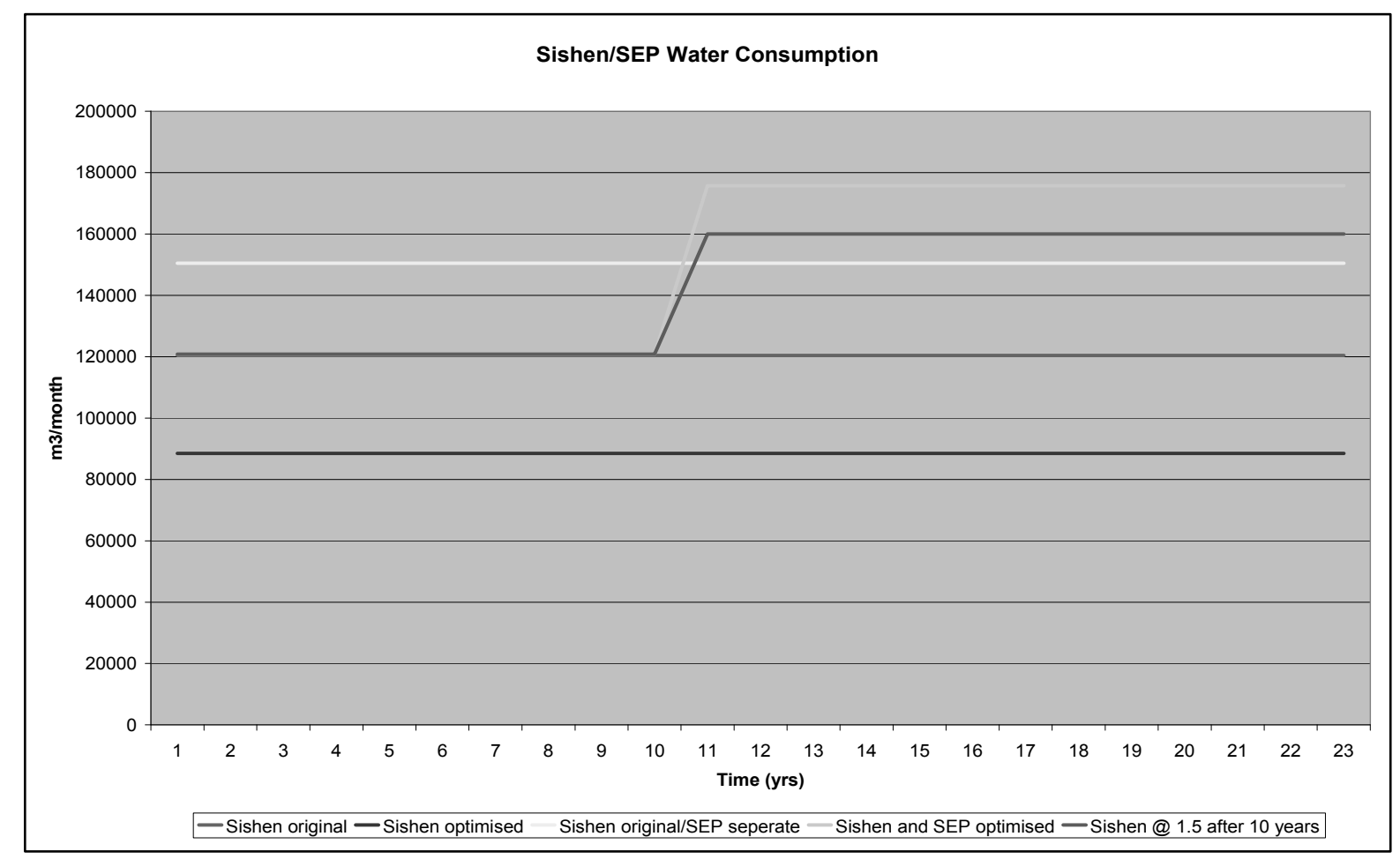

\section{Figure 3 Sishen/SEP water consumption}

\section{Conclusion}

It is therefore evident that the water consumption on the TSF complex has reduced significantly after the optimisation measures and even after the addition of the SEP plant. The impact of the additional consumption as a result of the new SEP plant was therefore minimised. 